\title{
Insulin Resistance, Visceral Adiposity Index and TyG Index in Genotype-4 Chronic HCV Patients and Their Relation to Hepatic Histopathology
}

\author{
Eman A. Sabet' ${ }^{1}$, Asmaa N. Mohammad ${ }^{2}$, Laila M. Yousef ${ }^{3}$, Ahmed R. H. Ahmed $^{4}$, Abeer Sheneef ${ }^{5}$ \\ ${ }^{1}$ Department of Internal Medicine, Faculty of Medicine, Sohag University, Sohag, Egypt \\ ${ }^{2}$ Department of Tropical Medicine and Gastroenterology, Faculty of Medicine, Sohag University, Sohag, Egypt \\ ${ }^{3}$ Department of Clinical Pathology, Faculty of Medicine, Sohag University, Sohag, Egypt \\ ${ }^{4}$ Department of Pathology, Faculty of Medicine, Sohag University, Sohag, Egypt \\ ${ }^{5}$ Department of Medical Microbiology and Immunology, Faculty of Medicine, Sohag University, Sohag, Egypt \\ Email: asmaanaser25@yahoo.co.uk
}

How to cite this paper: Sabet, E.A., Mohammad, A.N., Yousef, L.M., Ahmed, A.R.H. and Sheneef, A. (2016) Insulin Resistance, Visceral Adiposity Index and TyG Index in Genotype-4 Chronic HCV Patients and Their Relation to Hepatic Histopathology. Open Journal of Gastroenterology, 6, 249-264. http://dx.doi.org/10.4236/ojgas.2016.610030

Received: August 26, 2016

Accepted: October 16, 2016

Published: October 19, 2016

Copyright $\odot 2016$ by authors and Scientific Research Publishing Inc. This work is licensed under the Creative Commons Attribution International License (CC BY 4.0).

http://creativecommons.org/licenses/by/4.0/

\section{Abstract}

Introduction: Hepatitis $\mathrm{C}$ virus (HCV) genotype 4 is the most prevalent in Egypt. Visceral adiposity index (VAI) and (TyG) index are newly developed indices for assessment of metabolic syndrome (MS) and insulin resistance (IR). We aimed at comparing their levels in HCV-patients with healthy controls and validate their use for prediction of hepatic histopathological changes. Patient and Methods: 78 chronic $\mathrm{HCV}$-infected patients proven by PCR, viral genotyping and hepatic histopathology, and 67 healthy controls were enrolled. Presence of MS, Homeostasis Model Assessment for IR estimation (HOMA-IR), TyG index, and VAI were assessed. Results: HOMA-IR, TyG and frequency of MS were significantly higher in patients' group ( $p$ $<0.0001$ for each) in comparison to controls. In HCV patients, increased fasting blood glucose (FBG) was the only strong predictor of severe hepatic necro-inflammation. High FBG, older age, female sex, high AST, TyG, VAI, serum lipids abnormalities and presence of MS were all associated with severe fibrosis on univariate regression analysis. Only high AST, TyG, VAI and LDL were independent predictors of severe fibrosis. A model using the 4 parameters showed a strong validity in predicting advanced hepatic fibrosis (AUC 0.801; CI: $0.705-0.897, p<0001$ ). Female sex, high BMI, VAI, LDL and TG values are all significantly associated with moderate/severe steatosis on univariate analysis. Among them, high BMI and LDL are the strong predictors (AUC 0.738; CI $0.625-0.851, p=0.002$ ). Conclusion: HCV genotype 4 is significantly associated with MS and increased values of HOMA IR and TyG index. TyG index and VAI are valuable simple indices that could predict the histopathological changes in Egyptian CHC patients. 


\section{Keywords}

HCV, IR, TyG, VAI, Steatosis, Genotype 4

\section{Introduction and Aim of the Work}

Hepatitis $\mathrm{C}$ virus (HCV) is quiet prevalent globally. Genotype 1 was estimated to be the most prevalent worldwide (46.2\% of all HCV cases), followed by genotype 3 (30.1\%). Other genotypes comprise the remaining $36 \%$ of cases. Genotype 4 predominates in North Africa and Middle East countries including Egypt [1]. In fact, studies indicate that Egypt is enduring a large HCV disease burden, and is likely to be the most affected nation worldwide by this infection which makes HCV and its complications one of leading public health problems in Egypt [2].

Previous clinico-epidemiological studies postulated that metabolic syndrome, steatosis and insulin resistance occurring more in patients with hepatitis C virus [3] [4]. HCVinduced glucose intolerance was a pathological feature of insulin resistance. IR may have many serious effects in HCV patients. It may be associated with fibrosis progression of the liver tissue, failure to treatment response, and progression to hepatocellular carcinoma. Eradication of HCV by antiviral therapy has been shown to ameliorate IR, both in hepatic tissues and whole body. On the other hand, visceral obesity has been shown to enhance HCV-induced insulin resistance [4] [5] [6] [7].

Histologically, Hepatocyte steatosis is a feature associating many liver diseases including chronic HCV. Its prevalence among HCV patients ranges from $40 \%$ to $86 \%$ according to the genotype. Researchers have defined two main types of steatosis; one type is associated with metabolic syndrome (metabolic steatosis) and commonly found in patients infected by genotype 1 . The other one was reported in patients with genotype $3 \mathrm{a}$ in which fat accumulation correlates with HCV replication levels and disappears after successful antiviral therapy, without other known steatogenic cofactors suggesting a direct cytopathic effect of the virus (viral steatosis) [4] [8] [9].

Visceral adiposity is best evaluated by magnetic resonance imaging and was found to be correlated with liver fat accumulation in healthy subjects [10] and it was associated with severe inflammation and fibrosis in nonalcoholic steato-hepatitis. In other studies, waist circumference (WC) measurement was used as a surrogate marker of visceral adiposity and association was reported between it and hepatic steatosis in nonalcoholic fatty liver disease and in CHC patients [11] [12]. However, using WC alone to indicate visceral obesity is not entirely accurate as it does not help distinguishing subcutaneous and visceral fat mass; the latter being the most important factor in metabolic derangement [13] [14].

A mathematical model called "Visceral Adiposity Index (VAI)" was developed by Amato et al. [15] to overcome this problem. Both anthropometric measures (BMI and WC) and functional parameters (serum TG \& HDL-cholesterol) are used to calculate it. They consider it a simple surrogate marker of VA disease, as it showed a strong associ- 
ation with Euglycemic-hyperinsulinemic Clamp as a test of IR as well as with visceral adipose tissue (VAT) measured with MRI.

VAI has been studied in a specific cohort of patients with genotype 1 chronic hepatitis $\mathrm{C}$ and proved to be independently associated with both steatosis and necro-inflammatory activity and directly correlated with viral load [16].

Another group of investigators [17] proposed the product of plasma triglyceride and glucose concentrations as an index of IR (TyG index). The levels of both metabolites are strictly dependent on prevailing insulin concentrations, and the inclusion of a lipid parameter widens the concept of IR on different substrates. They concluded that the TyG index could be useful, low cost and easy-to-calculate surrogate for estimating insulin resistance in apparently healthy subjects. The index was validated in other studies [18] [19] [20] and was shown to be non-inferior to HOMA-IR, directly related to HCV viral load, and appears to have a similar performance to HOMA-IR, in predicting the severity of steatosis, but compares favorably in terms of cost and use in general clinical practice.

The present study is a case-control study aimed to compare the values of HOMA-IR, VAI and TyG indices in chronic HCV-infected Egyptian patients to those in healthy population and to determine the correlation of such indices to viral genotype and histopathological changes in infected patients.

\section{Patients and Methods}

This study is a prospective case-control study. Seventy-eight patients with chronic hepatitis $\mathrm{C}(\mathrm{CHC})$ among those admitted to departments of Internal Medicine and Tropical Medicine and attending the out-patient clinic of Sohag University Hospital during the period from 6/2013 to 12/2014 were included in our study. Inclusion criteria were; chronic HCV Naïve-patients, who were proved by positive HCV-Abs by ELISA for more than 6 months, positive PCR and had a histopathological diagnosis by liver biopsy.

Exclusion criteria were: patients with diabetes mellitus, Child-Pugh class B and C cirrhotic patients, patients with hepatocellular carcinoma, other causes of liver disease, anti-viral treatment experienced patients or immunosuppressive drug and/or regular use of steatosis-inducing drugs (corticosteroids, amiodarone, etc.).

In addition, 67 of age- and sex-matched healthy control individuals were included. The study was approved by the local Ethics Committee of Sohag Faculty of Medicine and it was performed in accordance with the principles of the Declaration of Helsinki. All participants assigned a written informed consent.

Personal data, full history and anthropometric measurements were obtained from all participants. Height, weight, and waist circumference were measured, and body mass index (BMI) was calculated for each included patient. Patients grouped in accordance with National Institutes of Health classification of obesity (1998); BMI $\left(\mathrm{kg} / \mathrm{m}^{2}\right)$ : Normal range 18.5 - 24.9, Overweight 25.0 - 29.9, Obesity $\geq 30$ [21]. WC was estimated mid-way between the lowest point of the thoracic cage and the iliac crest. High abnormal values 
are $\geq 94 \mathrm{~cm}$ for men and $\geq 80 \mathrm{~cm}$ for women according to International Diabetes Federation (IDF) criteria. Metabolic syndrome was diagnosed according to IDF criteria in 2006 [22]. Thorough clinical examination was performed for all patients as well as abdominal sonographic examination.

\subsection{Laboratory Testing}

The following tests were done for the participants:

- Two ml. venous blood collected on EDTA tube for complete blood picture (CBC) by CEII-DYN 3700 (Abbott Laboratories, USA).

- Twelve hours overnight fasting venous blood samples (about $10 \mathrm{ml}$ ) were collected in sterile tubes. Samples were immediately cooled to $4^{\circ} \mathrm{C}$ and centrifuged at 3000 rpm for 10 minutes. Serum was divided into three aliquots:

The first aliquot used immediately for measuring of: fasting plasma glucose, lipid profile (triglycerides, total cholesterol, HDL-c and LDL), liver enzymes (Alanine Aminotransferase (ALT), Aspartate Aminotransferase (AST), Alkaline phosphatase (ALP), Total bilirubin (TB) and serum Albumin by Cobas c311 Chemistry Analyzer System (Roche Diagnostics, Germany).

The second aliquot was used for detection of fasting insulin level (using Architect i2000, Abbott)

The third portion (only for patients) was collected in a sterile plain vacationer for HCV molecular testing;

\section{$R N A$ extraction}

HCV RNA was extracted from serum samples by the use of a fully automated QIA cube instrument using QIA amp Viral RNA Mini (Qiagen, Germany) according to the manufacturer's instructions. Extracted RNA was frozen at $-20^{\circ} \mathrm{C}$ till the time of use.

Quantitative Real time PCR for the detection of HCV RNA and the viral load: Using AgPath-ID ${ }^{\text {ts }}$ One-Step RT-PCR Reagents and 7500 Fast Real Time-PCR system (Applied Biosystems, USA) according to the manufacturer's instructions.

\section{HCV genotyping}

Using the VERSANT ${ }^{\oplus}$ HCV Amplification 2.0 Kit (LiPA) (Siemens Healthcare, USA); designed for reverse transcription and amplification of the $5^{\prime}$ untranslated region ( $5^{\prime}$ UTR) and core region of HCV genome sequentially in a single tube. Genomic HCV RNA is reverse transcribed into cDNA using HCV-specific primers, next the mixture is heated to activate the DNA polymerase and inactivate the reverse transcriptase simultaneously. Portions of the 5' UTR and core regions of the HCV genome are co-amplified from the cDNA using two pairs of biotinylated primers to produce two distinct biotinylated DNA fragments of 240 and 270 base pairs. The VERSANT HCV Genotype 2.0 Assay (LiPA) strips have 3 control lines and 22 parallel DNA probe lines containing sequences specific for HCV genotypes 1 to 6 . HCV genotypes are determined by aligning the assay strips with the kit reading card and comparing the line patterns from the assay strips with the patterns shown on the kit Interpretation Chart. 


\subsection{Calculation of Indices}

a) Homeostasis Model Assessment (HOMA) as estimates of Insulin resistance (IR): (HOMA-IR). It was calculated by using the following formula:

Fasting insulin $(U / \mathrm{mL}) X$ fasting glucose $(\mathrm{mmol} / \mathrm{L}) / 22.5$.

HOMA-IR values of $>2.7$ indicate IR [23] [24].

b) Visceral Adiposity Index (VAI)

VAI score was calculated as described by Amato et al. [15] using the following formulae and was differentiated according to sex:

$$
\begin{gathered}
\text { Males: } \mathrm{VAI}=\left\{\frac{w c}{(39.68+1.88 \times \mathrm{BMI})}\right\} \times\left\{\frac{\mathrm{TG}}{1.03}\right\} \times\left\{\frac{1.31}{\mathrm{HDL}}\right\} \\
\text { Females: } \mathrm{VAI}=\left\{\frac{w C}{(39.58+1.89 \times \mathrm{BMI})}\right\} \times\left\{\frac{\mathrm{TG}}{0.81}\right\} \times\left\{\frac{1.52}{\mathrm{HDL}}\right\}
\end{gathered}
$$

WC: waist circumference, TG: serum Triglycerides, HDL: High-density lipoproteincholesterol, BMI: Body mass index.

c) TyG index.

Was calculated using the following formula [19]:

$$
\text { Fasting triglycerides }(\mathrm{mg} / \mathrm{dl}) \times \text { fasting glucose }(\mathrm{mg} / \mathrm{dl}) / 2
$$

\subsection{Histopathological Evaluation}

Haematoxylin and eosin-stained and Masson's trichrome-stained sections of liver core biopsies were evaluated by a single pathologist without knowledge of the patients' clinical or blood samples data. The grade of necro-inflammation and stage of fibrosis were scored according to Scheuer's scoring system [25] and the degree of steatosis was evaluated according to the relative percentage of involved cells [4]. For Masson's trichrome staining (DDK Italia, Code 12-107); tissue sections were de-paraffinized, rehydrated, rinsed in running water and re-fixed in Bouin's solution for 1 hour at room temperature. After washing in tap water, the sections were stained by Weigert's iron hematoxylin working solution for 10 minutes before incubation in Biebrich acid fuchsin solution for 10 minutes followed by differentiation in phosphomolybdic-phosphotungstic acid solution for 10 - 15 minutes. The sections were incubated in aniline blue solution for 10 minutes; rinsed briefly in distilled water and differentiated in $1 \%$ acetic acid solution for 5 minutes. Finally, the sections were dehydrated and mounted as usual.

\subsection{Statistical Analysis}

The results were analyzed by IBM-SPSS version 20.0 for Windows; IBM Inc. MannWhitney $U$ test was used to compare continuous variables, and the correlations of continuous variables were evaluated by Pearson's correlation co-efficient test. Univariate and Multivariate Binary Logistic regression analyses were used to recognize the factors associated with hepatitis grading, staging and degree of steatosis. The validity of differ- 
ent parameters in predicting histopathological changes was determined by Receiver operating characteristic (ROC) curve. Significant and highly significant relationships were considered when P-value was $<0.05$ or $<0.001$, respectively.

\section{Results}

\subsection{Patient Demographic, Clinical and Laboratory Features}

Seventy-eight patients of genotype 4 chronic hepatitis C; confirmed by serology and PCR studies and 67 of age- and sex-matched control individuals were included in this study. Viral genotyping was determined and proved to be genotype 4 in all patients. Four of them had mixed infection with both genotype 4 and 1. Different statistical parameters for patients and controls are summarized in Table 1. Mean (SD) values of WC were within the normal range in males $\{81.0$ (4.9) \& 82.3 (2.9) in patients and controls

Table 1. Demographic, clinical and laboratory characteristics of the study population.

\begin{tabular}{|c|c|c|c|c|c|}
\hline \multicolumn{3}{|l|}{ Feature } & \multirow{2}{*}{$\begin{array}{l}\text { HCV patients } \\
\qquad(\mathrm{N}=78) \\
41.9(11.01)\end{array}$} & \multirow{2}{*}{$\begin{array}{c}\begin{array}{c}\text { Control } \\
(\mathrm{N}=67)\end{array} \\
43.4(10.9)\end{array}$} & \multirow{2}{*}{$\begin{array}{c}\text { P value } \\
0.479^{*}\end{array}$} \\
\hline Age (years) & - & Mean $(S D)$ & & & \\
\hline \multirow{2}{*}{ Sex } & - & males & 46 & 35 & \multirow{2}{*}{$0.41^{\star *}$} \\
\hline & - & females & 32 & 32 & \\
\hline WC (cm): Males & - & $\operatorname{Mean}(S D)$ & $81.0(4.9)$ & $82.3(2.9)$ & $0.029^{*}$ \\
\hline Females & - & Mean $(S D)$ & $86.5(7.1)$ & $81.8(3.3)$ & $0.002^{*}$ \\
\hline BMI & - & Mean $(S D)$ & $27.7(3.7)$ & $28.2(1.5)$ & $0.04^{*}$ \\
\hline \multirow{2}{*}{ Hypertension } & - & No & 69 & 59 & \multirow{2}{*}{$0.94^{* *}$} \\
\hline & - & Yes & 9 & 8 & \\
\hline ALT & - & Mean $(S D)$ & $43.5(17.0)$ & $29.3(12.4)$ & $<0.0001^{*}$ \\
\hline AST & - & $\operatorname{Mean}(S D)$ & $40(13.0)$ & $28(11.5)$ & $<0.0001^{*}$ \\
\hline ALB & - & Mean $(S D)$ & $4.0(0.3)$ & $4.1(0.26)$ & $0.30^{*}$ \\
\hline PT (seconds) & - & Mean $(S D)$ & $12.2(1.1)$ & $12.2(1.2)$ & $0.82^{*}$ \\
\hline PC (\%) & - & Mean $(S D)$ & $92.8(10.7)$ & $91.5(10.7)$ & $0.49^{*}$ \\
\hline Fasting glucose (mmol/L) & - & Mean $(S D)$ & $5.5(0.6)$ & $4.7(0.5)$ & $<0.0001^{*}$ \\
\hline Fasting insulin $(\mathrm{U} / \mathrm{ml})$ & - & $\operatorname{Mean}(S D)$ & $13.4(6.5)$ & $8.5(7.3)$ & $<0.0001^{*}$ \\
\hline $\mathrm{HDL}(\mathrm{mg} / \mathrm{dl})$ & - & Mean $(S D)$ & $50.4(13.7)$ & $54.2(10.9)$ & $0.011^{\star}$ \\
\hline $\mathrm{LDL}(\mathrm{mg} / \mathrm{dl})$ & - & Mean $(S D)$ & $85.2(24.4)$ & $39.9(19.0)$ & $<0.0001^{*}$ \\
\hline Triglyceride (mg/dl) & - & Mean $(S D)$ & $126.1(40.6)$ & $107.6(34.5)$ & $0.10^{*}$ \\
\hline Cholesterol (mg/dl) & - & Mean $(S D)$ & $128.9(45.2)$ & $112.2(33.6)$ & $0.044^{\star}$ \\
\hline \multirow{2}{*}{ Metabolic syndrome } & - & No & 44 & 57 & \multirow{2}{*}{$<0.0001^{\star *}$} \\
\hline & - & Yes & 34 & 10 & \\
\hline HOMA-IR & - & Mean $(S D)$ & $3.1(1.6)$ & $1.8(1.6)$ & $<0.0001^{*}$ \\
\hline $\log 10($ TyG) & - & Mean $(S D)$ & $3.76(0.17)$ & $3.03(0.20)$ & $<0.0001^{*}$ \\
\hline VAI & - & Mean $(S D)$ & $3.8(2.4)$ & $3.1(1.8)$ & $0.195^{\star}$ \\
\hline
\end{tabular}

Mann-Whitney ${ }^{\star}$, Chi-square**, significant relationships are highlighted. 
respectively\} but it was significantly high in female patients in comparison to control groups $\{86.5$ (7.1) \& 81.8 (3.3) in patients and controls respectively, $p<0.002\}$. The majority of the patients $(n=48)$ were overweight and 16 patients were obese according to value of BMI. Nine of the investigated cases and eight of the control group were hypertensive. Regarding liver function tests, $67 \%(n=52)$ and $59 \%(n=46)$ of HCVpatients had raised serum levels of ALT and AST, respectively. The patients had significantly higher serum ALT and AST levels compared to the control group (MannWhitney, $p<0.0001$ for both analyses). The mean values for serum albumin, prothrombin time (PT), prothrombin concentration (PC) and platelet count are within normal. Metabolic syndrome was diagnosed in $43.6 \%$ of the cases and it was more incident among HCV patients compared to the control group $(p<0.0001)$. Insulin resistance as determined by HOMA-IR is significantly more frequent among HCV patients compared to control group $(p<0.0001)$. Similarly, TyG values were significantly higher than control group $(p<0.0001)$. Although the mean (SD) value of VAI was higher in patients than controls, the difference was not statistically significant.

The necro-inflammatory liver lesions (Figure 1(A) and Figure 1(B)) were graded as 1, 2, 3 and 4 in 26, 38, 12 and 2 patients, respectively and the stage of fibrosis (Figure $1(C)$ and Figure 1(D)) was stated as $0,1,2$ and 3 in 8, 26, 28 and 16 patients, respectively. Histological evidence of micro-or macro-vesicular steatosis was demonstrated in 56 patients (71.8\%) with mean (SD) and median percentage of the affected cells was $18 \%(22 \%)$ and $10 \%$, respectively. Moderate/severe degree of steatosis (involving $>30 \%$ of the cells; Figure 1(B)) was recorded in 20 cases (25.6\%).

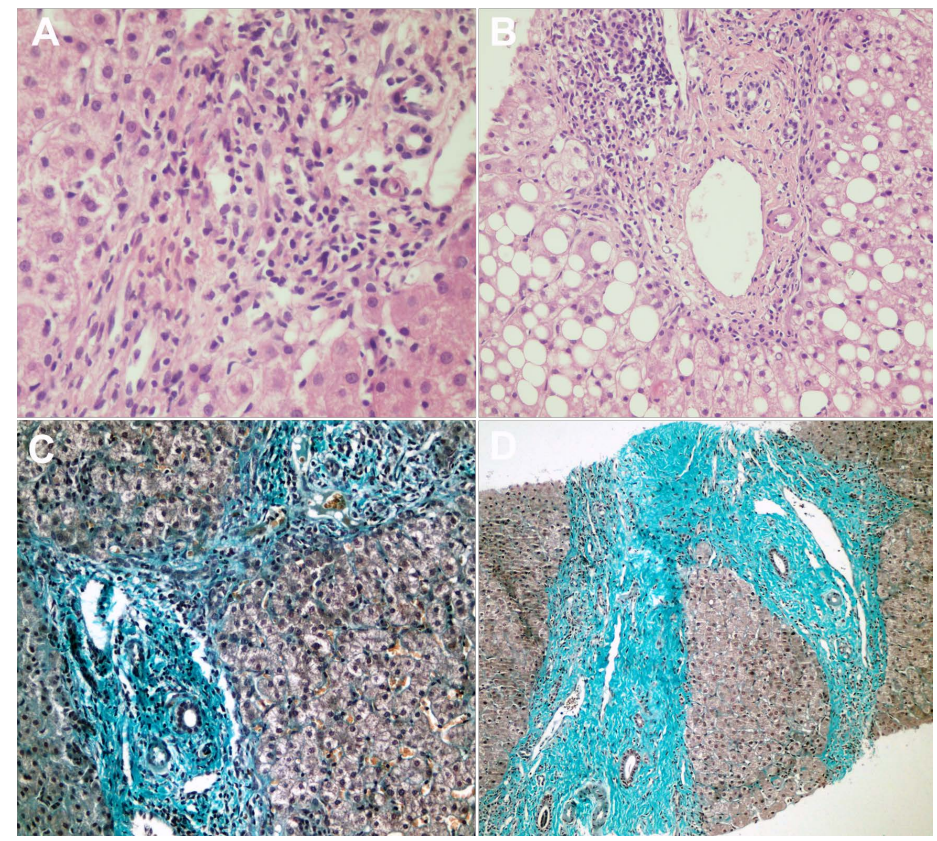

Figure 1. Grade 2 (A) and 3 (B) necro-inflammatory lesions and stage 2 (C) and 3 (D) fibrosis with severe steatosis $(B)$ of the liver in patients with chronic hepatitis $\mathrm{C}$ infection. $\mathrm{H}$ \& $\mathrm{E}$ stain (A and $B)$ and Masson's trichrome stain $((C)$ and $(D))$; magnification is $400 \times(A), 200 \times((B)$ and (C)) and $100 \times(D)$. 


\subsection{Factors Associated with HOMA IR, TyG and VAI}

The mean (SD) values of HOMA IR and mean (SD) of $\log 10$ (TyG) scores in hepatitis C patients were 3.1 (1.6) and 3.76 (0.17), respectively. According to the previously described cut-off value of HOMA IR (more than 2.7); 56 of the patients have insulin resistance (71.8\%). Several clinical, pathological and biochemical parameters were associated with high HOMA IR, with high TyG and with high VAI values (Table 2).

Table 2. Correlations between HOMA-IR, TyG, and VAI with different variables in HCV-patients.

\begin{tabular}{|c|c|c|c|c|c|c|}
\hline \multirow{2}{*}{ Feature } & \multicolumn{2}{|c|}{ HOMA-IR } & \multicolumn{2}{|c|}{$\log 10(\mathrm{TyG})$} & \multicolumn{2}{|c|}{ VAI } \\
\hline & $\mathrm{R}$ & $\mathrm{P}$ & $\mathrm{R}$ & $\mathrm{P}$ & $\mathrm{R}$ & $\mathrm{P}$ \\
\hline Age & -0.07 & 0.57 & 0.054 & 0.636 & 0.13 & 0.25 \\
\hline Female sex & 0.17 & 0.12 & 0.294 & 0.009 & 0.51 & $<0.0001$ \\
\hline BMI & -0.15 & 0.19 & 0.257 & 0.023 & 0.39 & 0.001 \\
\hline WC & 0.55 & 0.63 & 0.139 & 0.226 & 0.44 & $<0.0001$ \\
\hline Hypertension & -0.06 & 0.60 & 0.220 & 0.053 & 0.220 & 0.052 \\
\hline ALT & -0.18 & 0.10 & 0.086 & 0.453 & 0.007 & 0.96 \\
\hline AST & -0.25 & 0.012 & 0.238 & 0.036 & 0.18 & 0.17 \\
\hline ALB & 0.35 & 0.002 & 0.255 & 0.024 & 0.18 & 0.12 \\
\hline $\mathrm{PT}$ & -0.04 & 0.71 & 0.183 & 0.109 & 0.093 & 0.42 \\
\hline PC & 0.03 & 0.81 & -0.256 & 0.024 & -0.238 & 0.036 \\
\hline INR & 0.048 & 0.68 & -0.209 & 0.066 & 0.068 & 0.56 \\
\hline Platelet count & -0.01 & 0.92 & -0.20 & 0.861 & -0.012 & 0.31 \\
\hline $\mathrm{FG}(\mathrm{mmol} / \mathrm{L})$ & 0.28 & 0.014 & 0.677 & $<0.0001$ & 0.52 & $<0.0001$ \\
\hline Fasting insulin & 0.97 & $<0.0001$ & -0.062 & 0.587 & -0.06 & 0.62 \\
\hline HOMA IR & & & 0.074 & 0.517 & 0.061 & 0.59 \\
\hline TyG & 0.41 & 0.72 & & & 0.81 & $<0.0001$ \\
\hline VAI & 0.061 & 0.59 & 0.771 & $<0.0001$ & & \\
\hline HDL & 0.08 & 0.51 & -0.697 & $<0.0001$ & -0.79 & $<0.0001$ \\
\hline LDL & 0.27 & 0.018 & 0.713 & $<0.0001$ & 0.67 & $<0.0001$ \\
\hline Triglyceride mg/dl & -0.035 & 0.76 & 0.937 & $<0.0001$ & 0.84 & $<0.0001$ \\
\hline Cholesterol & 0.15 & 0.19 & 0.716 & $<0.0001$ & 0.67 & $<0.0001$ \\
\hline Log 10 PCR & 0.16 & 0.16 & 0.003 & 0.982 & 0.13 & 0.26 \\
\hline Grade & 0.220 & 0.053 & 0.147 & 0.201 & 0.135 & 0.239 \\
\hline Stage & -0.099 & 0.387 & 0.161 & 0.158 & 0.253 & 0.026 \\
\hline Steatosis & 0.183 & 0.108 & 0.253 & 0.025 & 0.333 & 0.003 \\
\hline MS & 0.05 & 0.68 & 0.826 & $<0.0001$ & 0.83 & 0.0001 \\
\hline
\end{tabular}

$\mathrm{R}=$ Pearson's correlation co-efficient, $p=\mathrm{p}$ value, significant relationships are highlighted. 


\subsection{Factors Associated with Histopathological Findings}

The association of different host and viral factors with liver histopathological changes of genotype $4 \mathrm{CHC}$ patients namely grade and stage of the disease and severity of steatosis was evaluated. The grade of hepatitis was classified into two main categories; mild/moderate hepatitis $(\mathrm{n}=64)$ including grade I and II necro-inflammatory lesions and severe hepatitis $(\mathrm{n}=14)$ including grade III and IV necro-inflammatory lesions. Similarly the degree of fibrosis was classified into two categories; no/early fibrosis ( $\mathrm{n}=$ 34) including stages 0 and I disease and more advanced fibrosis $(n=34)$ including stages II, III and IV. Steatosis was classified as absent-mild at $<30 \%$ or moderate-severe at $>30 \%$

On univariate logistic regression analysis, increased fasting blood glucose, increased HOMA IR and high LDL were associated with severe necro-inflammatory lesions of the liver. On multivariate regression analysis, fasting blood glucose level can predict the severity of necro-inflammatory lesions (Table 3). Older age, female sex, high AST, high TyG score, high VAI index, low HDL, high LDL, high TG, high cholesterol level and presence of MS were all associated with severe fibrosis on univariate binary regression analysis (Table 3). Multivariate logistic regression analysis showed that the following parameters were independent predictors of severe fibrosis: high AST level, high TyG score, high VAI index and high LDL level (Table 3). Receiver operating characteristic (ROC) curve showed a strong validity of the model using these four parameters in predicting advanced hepatic fibrosis (AUC 0.801; SE 0.049; CI0.705 - 0.897, $p<0001$, Figure 2(A)).

The univariate and multivariate comparisons of variables linked to moderate/severe steatosis (>30\%) were reported in Table 3. Although female sex, high BMI,VAI, TyG, LDL and TG values were all significantly associated with moderate/severe steatosis $(>30 \%)$ on univariate analysis, only high BMI and high LDL levels are the strong predictors of moderate/severe steatosis on multivariate logistic regression analyses. ROC curve analyses showed a significant validity of the model using BMI and LDL to predict high degree of steatosis (AUC 0.738; SE 0.058; CI $0.625-0.851, p=0.002$, Figure 2(B)).

\section{Discussion}

Association between CHC and metabolic disorders manifested by metabolic syndrome, IR, Diabetes mellitus and hepatic steatosis was proven in several previous studies. The underlying mechanisms of metabolic derangements and degree of affection may vary in different population or in relation to viral genotype [4] [7] [8] [9]. New indices such as VAI and TyG, which were proposed to be surrogate indicators of the metabolic abnormalities accompanying IR [15] [16] [17] [18], were found to valuable predictors to histopathological changes occurring in HCV genotype 1 [10] [19]. To our knowledge, this is the first study to compare such indices in Egyptian genotype $4 \mathrm{HCV}$ patients with healthy controls and validate its role in prediction of histopathological changes namely necro-inflammation, fibrosis, and/or steatosis.

Liver biopsy is the gold standard method for assessing hepatic fibrosis and steatosis. 
Table 3. Univariate and Multivariate binary regression analysis of factors associated with grade and stage of hepatitis and degree of steatosis.

\begin{tabular}{|c|c|c|c|c|}
\hline Feature & $\begin{array}{l}\text { Univariate regression } \\
\text { co-efficient }(95 \% \mathrm{CI})\end{array}$ & $P$ value & $\begin{array}{l}\text { Multivariate regression } \\
\text { co-efficient }(95 \% \mathrm{CI})\end{array}$ & $\mathrm{P}$ value \\
\hline \multicolumn{5}{|c|}{ Grade of necro-inflammatory liver disease: } \\
\hline Fasting blood glucose & $3.012(1.187: 7.641)$ & 0.020 & $3.012(1.187: 7.641)$ & 0.020 \\
\hline HOMA IR & $1.513(0.951: 2.409)$ & 0.081 & $1.313(0.825: 2.089)$ & 0.194 \\
\hline LDL & 1.024 (0.990: 1.050) & 0.069 & $1.009(0.968: 1.041)$ & 0.563 \\
\hline \multicolumn{5}{|c|}{ Stage of fibrosis } \\
\hline Age & 1.048 (1.004: 1.094) & 0.034 & $1.044(0.983: 1.109)$ & 0.157 \\
\hline Female & 3.60 (1.33: 9.75) & 0.012 & $14.62(0.979: 135.85)$ & 0.075 \\
\hline AST & $1.056(1.015: 1.098)$ & 0.007 & $1.101(1.041: 1.165)$ & 0.001 \\
\hline TyG & 1.004 (1.000: 1.008) & 0.033 & 0.987 (0.977: 0.997) & 0.014 \\
\hline VAI & 1.39 (1.09: 1.77) & 0.007 & $2.068(1.146: 3.730)$ & 0.016 \\
\hline HDL & $0.961(0.927: 0.997)$ & 0.034 & 1.098 (0.997: 1.204) & 0.055 \\
\hline LDL & 1.03 (0.1.008: 1.052) & 0.007 & 1.046 (1.009: 1.086) & 0.016 \\
\hline $\mathrm{TG} \mathrm{mg} / \mathrm{dl}$ & 1.013 (1.001: 1.026) & 0.029 & $1.032(0.953: 1.116)$ & 0.44 \\
\hline \multicolumn{5}{|c|}{ Steatosis } \\
\hline Female sex & 2.850 (1.002: 8.109) & 0.050 & 3.472 (0.497: 24.270) & 0.210 \\
\hline BMI & $1.202(1.045: 1.383)$ & 0.010 & $1.230(1.060: 1.427)$ & 0.006 \\
\hline TyG & 1.004 (1.000: 1.008) & 0.054 & $0.967(0.925: 1.010)$ & 0.133 \\
\hline VAI & 1.287 (1.043: 1.587) & 0.019 & $0.762(0.407: 1.427)$ & 0.395 \\
\hline LDL & $1.022(1.000: 1.045)$ & 0.054 & 1.027 (1.002: 1.053$)$ & 0.035 \\
\hline TG (mg/dl) & 1.013 (1.000: 1.026) & 0.054 & 0.995 (0.970: 1.021) & 0.721 \\
\hline
\end{tabular}

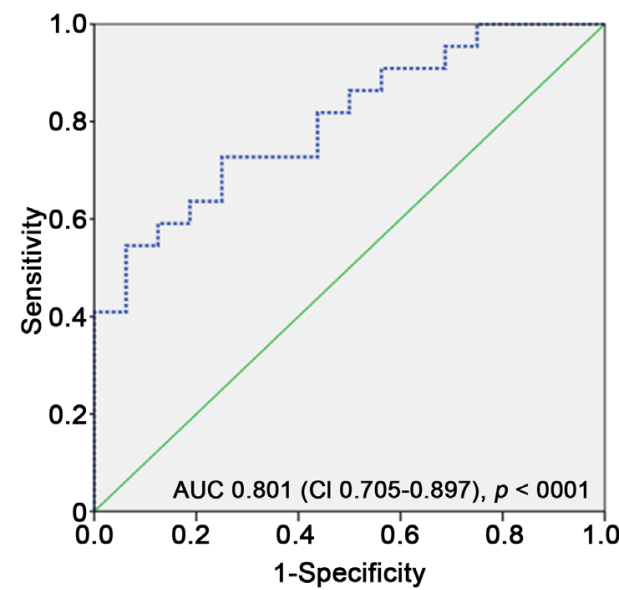

(A)



(B)

Figure 2. ROC curve for predicting moderate/severe fibrosis using AST, TyG, VAI and LDL values (A) and moderate/severe steatosis using BMI \& LDL values (B). 
Previous guidelines recommended it as preliminary step to decide Interferon-based therapy [26]. All patients in this study had performed liver biopsy as a part of pretreatment assessment before the beginning of anti-viral therapy for treatment of $\mathrm{HCV}$ in Egypt. As we mentioned, all samples were examined by a single pathologist to avoid inter-observer variability. With the development of anti-protease therapy for HCV, the need for liver biopsy is minimized and the presence of simple cheap non-invasive predictors may be sufficient to evaluate histopathological changes [27].

By comparing the demographic, clinical and laboratory parameters in HCV patients and control groups, we found that metabolic syndrome was significantly prevalent among HCV group $(p<0.0001)$; our diagnosis was dependent on IDF criteria [22] which included WC, TG, HDL, hypertension and fasting serum glucose level. WC was significantly increased only in female patients, while it was within normal range in male patients, however, the abnormalities in other components; namely HDL, TG \& fasting glucose seems to be the determinant factors for metabolic syndrome in this study. In fact, ethnic variations are well known in the determination of standards values for WC. In Egypt we use the European values but the development of our own standards will be valuable and highly recommended. We previously reported the association of CHC with metabolic syndrome in our locality [28] and it was also reported in many studies globally [29] [30] [31] [32]. A Brazilian study on genotype 1 HCV [33] had reported high prevalence of metabolic syndrome among HCV patients even in patients without type 2 diabetes or obesity. They found that metabolic syndrome was significantly associated with hypertension, insulin resistance and increased abdominal fat.

In this study, HOMA-IR and TyG values were significantly higher among patients as compared with control group ( $p<0.0001$ for both). The association of CHC with IR is well documented in several previous studies and with almost all genotypes including genotype 4 [4] [5] [6] [7]. The underlying mechanisms of HCV-induced IR have been previously studied. HCV induces IR with both hepatic and peripheral manner with some differences in different genotypes [34]. TyG index has been recently emerged as a simple surrogate index for IR and proved in several studies to be non-inferior to HOMA IR when compared to euglycemic-hyperinsulinemic clamp test [17] [18] [19]. A single study reported the significance of its measurement in CHC genotype 1 but it didn't compare it to healthy controls [20].

VAI; a novel sex-specific index was suggested as a valuable indicator of "visceral adipose function" and insulin sensitivity [15] was calculated in this study for both patients and controls. The values although higher in patients but the difference was not statistically significant. No reports are available till now comparing VAI values in $\mathrm{HCV}$ patients and controls. One study tested its correlation to viral load and histological findings in genotype 1-HCV patients [16].

IR in addition to its role in development of type 2 diabetes and increased cardiovascular risk [35], has emerged as an important prognostic factor for the clinical course of $\mathrm{HCV}$ infection. It has been linked to increased disease severity, extra hepatic manifestations, and decreased response to antiviral therapy [6] [36], progression of hepatic fibro- 
sis and development of hepatocellular carcinoma [37]. Moreover, HCV affects lipid metabolism and induces hepatic steatosis by genotype-specific mechanisms; HCV genotype 1 can cause metabolic hepatic steatosis through its interactions with factors related to visceral adiposity while HCV genotype 3 causes mainly viral hepatic steatosis. Both insulin resistance and hepatic steatosis are related to hepatic inflammation and fibrosis, and might enhance these conditions [3]. Genotype 4 is the least studied in previous literatures.

In the present study we tested the correlations between HOMA IR, TyG and VAI and other clinical, laboratory and histopathogical variables in HCV patients. HOMA IR was significantly correlated only with AST, serum albumin \& LDL levels. On the other hand; TyG had significant correlations with female sex, BMI, AST, serum albumin, prothrombin concentration, and all elements of serum lipids. It was correlated significantly also with hepatic steatosis, VAI and presence of metabolic syndrome. VAI showed similar significant correlations as TyG, in addition to a significant correlation with stage of hepatic fibrosis. None of the tested indices had a significant correlation with viral load in this study.

Petta et al. [20] found TyG was independently associated with WC, total cholesterol, presence of arterial hypertension, viral load and steatosis. HOMA was significantly associated with WC and steatosis. No independent associations were found between both TyG and HOMA and fibrosis or SVR in their study. They reported similar performance of TyG and HOMA in ROC model in predicting moderate to severe steatosis in HCV patients. On the other hand, several researchers found that serum insulin concentrations and HOMA-IR index scores were positively correlated with the severity of hepatic fibrosis [5] [6] [38] [39], Yoneda et al. stated that in patients with HCV, insulin resistance is more strongly associated with viral load than visceral obesity [40].

In their study on genotype $1 \mathrm{HCV}$, Petta et al. [16] found VAI score was independently associated with higher HOMA score, viral load, necro-inflammatory activity and steatosis. The same researchers claimed that VAI score was linked to severe fibrosis in non-alcoholic fatty liver disease (NAFLD) [41], Whereas others [42] found VAI is neither related to the severity of hepatic inflammation nor fibrosis in non-diabetic patients with NAFLD.

When univariate and multivariate binary regression analyses were performed to find variables which could predict histological finding in patients with HCV genotype 4. High fasting serum glucose, HOMA IR and LDL were all associated with severe necro-inflammation but fasting glucose was the only predictor on multivariate analysis. Several factors were associated with severe fibrosis, but among them high AST, TyG, VAI \& LDL were strong independent predictors; a strong validity of the model using these four parameters in predicting advanced hepatic fibrosis was shown. Moderate to severe steatosis could be predicted more in female patient, and in patients with high BMI, VAI, LDL and TG. The independent risk factors for severe steatosis were high BMI and High LDL, a significantly valid model using BMI and LDL could be used to predict high degree of steatosis. 


\section{Conclusion}

In conclusion, the present study showed significant association of HCV genotype 4 with increased HOMA IR, TyG score and the presence of metabolic syndrome in comparison to controls. TyG \& VAI are simple indices that could be of value in prediction of histopathological changes however further studies are needed to evaluate their accuracy.

\section{Acknowledgements}

The authors are grateful to all who participated in the study.

\section{Funding}

All needed investigations were held in Sohag university hospital, with no any external funding corporation.

\section{Ethical Approval}

The study protocol was approved by the local ethics committee of scientific research in Sohag University, Faculty of Medicine and all patients gave their consent prior to the study.

\section{Disclosure Statement}

All authors declare that there are no financial or other conflicts of interest.

\section{References}

[1] Messina, J.P., Humphreys, I., Flaxman, A., Brown, A., Cooke, G.S., Pybus, O.G. and Barnes, E. (2015) Global Distribution and Prevalence of Hepatitis C Virus Genotypes. Hepatology, 61, 77-87. http://dx.doi.org/10.1002/hep.27259

[2] Mohamoud, Y.A., Mumtaz, G.R., Riome, S., Miller, D. and Abu-Raddad, L.J. (2013) The Epidemiology of Hepatitis C Virus in Egypt: A Systematic Review and Data Synthesis. BMC Infectious Diseases, 13, 1. http://dx.doi.org/10.1186/1471-2334-13-288

[3] Kawaguchi, Y. and Mizuta, T. (2014) Interaction between Hepatitis C Virus and Metabolic Factors. World Journal of Gastroenterology: WJG, 20, 2888-2901. http://dx.doi.org/10.3748/wjg.v20.i11.2888

[4] Del Campo, J.A. and Romero-Gómez, M. (2009) Steatosis and Insulin Resistance in Hepatitis C: A Way Out for the Virus. World Journal of Gastroenterology, 15, 5014-5019. http://dx.doi.org/10.3748/wjg.15.5014

[5] D'souza, R., Sabin, C. and Foster, G. (2005) Insulin Resistance Plays a Significant Role in Liver Fibrosis in Chronic Hepatitis $\mathrm{C}$ and in the Response to Antiviral Therapy. The American Journal of Gastroenterology, 100, 1509-1515. http://dx.doi.org/10.1111/j.1572-0241.2005.41403.x

[6] Hui, J.M., Sud, A., Farrell, G.C., Bandara, P., Byth, K., Kench, J.G., McCaughan, G.W. and George, J. (2003) Insulin Resistance Is Associated with Chronic Hepatitis C and Virus Infection Fibrosis Progression. Gastroenterology, 125, 1695-1704.

http://dx.doi.org/10.1053/j.gastro.2003.08.032

[7] Moucari, R., Asselah, T., Cazals-Hatem, D., Voitot, H., Boyer, N., Ripault, M.P., Sobesky, 
R., Martinot-Peignoux, M., Maylin, S. and Nicolas-Chanoine, M.H. (2008) Insulin Resistance in Chronic Hepatitis C: Association with Genotypes 1 and 4, Serum HCV RNA Level, and Liver Fibrosis. Gastroenterology, 134, 416-423.

http://dx.doi.org/10.1053/j.gastro.2007.11.010

[8] Gordon, A., McLean, C.A., Pedersen, J.S., Bailey, M.J. and Roberts, S.K. (2005) Hepatic Steatosis in Chronic Hepatitis B and C: Predictors, Distribution and Effect on Fibrosis. Journal of Hepatology, 43, 38-44. http://dx.doi.org/10.1016/j.jhep.2005.01.031

[9] Lonardo, A., Adinolfi, L.E., Loria, P., Carulli, N., Ruggiero, G. and Day, C.P. (2004) Steatosis and Hepatitis C Virus: Mechanisms and Significance for Hepatic and Extrahepatic Disease. Gastroenterology, 126, 586-597. http://dx.doi.org/10.1053/j.gastro.2003.11.020

[10] Chan, D., Watts, G., Ng, T., Hua, J., Song, S. and Barrett, P. (2006) Measurement of Liver Fat by Magnetic Resonance Imaging: Relationships with Body Fat Distribution, Insulin Sensitivity and Plasma Lipids in Healthy Men. Diabetes, Obesity and Metabolism, 8, 698702. http://dx.doi.org/10.1111/j.1463-1326.2005.00543.x

[11] Van der Poorten, D., Milner, K.L., Hui, J., Hodge, A., Trenell, M.I., Kench, J.G., London, R., Peduto, T., Chisholm, D.J. and George, J. (2008) Visceral Fat: A Key Mediator of Steatohepatitis in Metabolic Liver Disease. Hepatology, 48, 449-457.

http://dx.doi.org/10.1002/hep.22350

[12] Marchesini, G., Brizi, M., Bianchi, G., Tomassetti, S., Bugianesi, E., Lenzi, M., McCullough, A.J., Natale, S., Forlani, G. and Melchionda, N. (2001) Nonalcoholic Fatty Liver Disease a Feature of the Metabolic Syndrome. Diabetes, 50, 1844-1850. http://dx.doi.org/10.2337/diabetes.50.8.1844

[13] Pouliot, M.-C., Després, J.-P., Lemieux, S., Moorjani, S., Bouchard, C., Tremblay, A., Nadeau, A. and Lupien, P.J. (1994) Waist Circumference and Abdominal Sagittal Diameter: Best Simple Anthropometric Indexes of Abdominal Visceral Adipose Tissue Accumulation and Related Cardiovascular Risk in Men and Women. The American Journal of Cardiology, 73, 460-468. http://dx.doi.org/10.1016/0002-9149(94)90676-9

[14] Dixon, J.B., Bhathal, P.S. and O’brien, P.E. (2001) Nonalcoholic Fatty Liver Disease: Predictors of Nonalcoholic Steatohepatitis and Liver Fibrosis in the Severely Obese. Gastroenterology, 121, 91-100. http://dx.doi.org/10.1053/gast.2001.25540

[15] Amato, M.C., Giordano, C., Galia, M., Criscimanna, A., Vitabile, S., Midiri, M. and Galluzzo, A. (2010) Visceral Adiposity Index A Reliable Indicator of Visceral Fat Function Associated with Cardiometabolic Risk. Diabetes Care, 33, 920-922.

http://dx.doi.org/10.2337/dc09-1825

[16] Petta, S., Amato, M., Cabibi, D., Camma, C., Di Marco, V., Giordano, C., Galluzzo, A. and Craxì, A. (2010) Visceral Adiposity Index Is Associated with Histological Findings and High Viral Load in Patients with Chronic Hepatitis C Due to Genotype 1. Hepatology, 52, 1543-1552. http://dx.doi.org/10.1002/hep.23859

[17] Simental-Mendía, L.E., Rodríguez-Morán, M. and Guerrero-Romero, F. (2008) The Product of Fasting Glucose and Triglycerides as Surrogate for Identifying Insulin Resistance in Apparently Healthy Subjects. Metabolic Syndrome and Related Disorders, 6, 299-304. http://dx.doi.org/10.1089/met.2008.0034

[18] Vasques, A.C.J., Novaes, F.S., de Oliveira, M., Souza, J.R.M., Yamanaka, A., Pareja, J.C., Tambascia, M.A., Saad, M.J.A. and Geloneze, B. (2011) TyG Index Performs Better than HOMA in a Brazilian Population: A Hyperglycemic Clamp Validated Study. Diabetes Research and Clinical Practice, 93, e98-e100. http://dx.doi.org/10.1016/j.diabres.2011.05.030

[19] Gastaldelli, A., Folli, F. and DeFronzo, R. (2010) The Product of Triglycerides and Glucose as Index of Insulin Resistance. Validation in the SAM Study. Journal of Clinical Endocri- 
nology of Metabolism, EPUB.

[20] Petta, S., Di Marco, V., Di Stefano, R., Cabibi, D., Camma, C., Marchesini, G. and Craxì, A. (2011) TyG Index, HOMA Score and Viral Load in Patients with Chronic Hepatitis C Due to Genotype 1. Journal of Viral Hepatitis, 18, e372-e380. http://dx.doi.org/10.1111/j.1365-2893.2011.01439.x

[21] World Health Organization (2000) Obesity: Preventing and Managing the Global Epidemic. World Health Organization.

[22] Alberti, K.G.M.M., Zimmet, P. and Shaw, J. (2006) Metabolic Syndrome-A New WorldWide Definition. A Consensus Statement from the International Diabetes Federation. Diabetic Medicine, 23, 469-480. http://dx.doi.org/10.1111/j.1464-5491.2006.01858.x

[23] McAuley, K.A., Williams, S.M., Mann, J.I., Walker, R.J., Lewis-Barned, N.J., Temple, L.A. and Duncan, A.W. (2001) Diagnosing Insulin Resistance in the General Population. Diabetes Care, 24, 460-464. http://dx.doi.org/10.2337/diacare.24.3.460

[24] Matsuda, M. and DeFronzo, R.A. (1999) Insulin Sensitivity Indices Obtained from Oral Glucose Tolerance Testing: Comparison with the Euglycemic Insulin Clamp. Diabetes Care, 22, 1462-1470. http://dx.doi.org/10.2337/diacare.22.9.1462

[25] Scheuer, P.J. (1991) Classification of Chronic Viral Hepatitis: A Need for Reassessment. Journal of Hepatology, 13, 372-374. http://dx.doi.org/10.1016/0168-8278(91)90084-O

[26] Yee, H.S., Currie, S.L., Darling, J.M. and Wright, T.L. (2006) Management and Treatment of Hepatitis C Viral Infection: Recommendations from the Department of Veterans Affairs Hepatitis C Resource Center Program and the National Hepatitis C Program Office. The American Journal of Gastroenterology, 101, 2360-2378. http://dx.doi.org/10.1111/j.1572-0241.2006.00754.x

[27] Yee, H.S., Chang, M.F., Pocha, C., Lim, J., Ross, D., Morgan, T.R. and Monto, A. (2012) Update on the Management and Treatment of Hepatitis C Virus Infection: Recommendations from the Department of Veterans Affairs Hepatitis C Resource Center Program and the National Hepatitis C Program Office. The American Journal of Gastroenterology, 107, 669-689. http://dx.doi.org/10.1038/ajg.2012.48

[28] Sabet, E. and El Aal, A. (2015) Hepatitis C Virus Infection and Metabolic Syndrome-A Community Based Study in Sohag University Hospital. Journal of Diabetes \& Metabolism, S13, 011. http://dx.doi.org/10.4172/2155-6156.s13-011

[29] Huang, J.-F., Chuang, W.-L., Yu, M.-L., Yu, S.-H., Huang, C.-F., Huang, C.-I., Yeh, M.-L., Hsieh, M.-H., Yang, J.-F. and Lin, Z.-Y. (2009) Hepatitis C Virus Infection and Metabolic Syndrome-A Community-Based Study in an Endemic Area of Taiwan. The Kaohsiung Journal of Medical Sciences, 25, 299-305. http://dx.doi.org/10.1016/S1607-551X(09)70520-0

[30] Sheikh, M.Y., Choi, J., Qadri, I., Friedman, J.E. and Sanyal, A.J. (2008) Hepatitis C Virus Infection: Molecular Pathways to Metabolic Syndrome. Hepatology, 47, 2127-2133. http://dx.doi.org/10.1002/hep.22269

[31] Shaheen, M., Echeverry, D., Oblad, M.G., Montoya, M.I., Teklehaimanot, S. and Akhtar, A.J. (2007) Hepatitis C, Metabolic Syndrome, and Inflammatory Markers: Results from the Third National Health and Nutrition Examination Survey (NHANES III). Diabetes Research and Clinical Practice, 75, 320-326. http://dx.doi.org/10.1016/j.diabres.2006.07.008

[32] Younossi, Z.M. and McCullough, A.J. (2009) Metabolic Syndrome, Non-Alcoholic Fatty Liver Disease and Hepatitis C Virus: Impact on Disease Progression and Treatment Response. Liver International, 29, 3-12. http://dx.doi.org/10.1111/j.1478-3231.2008.01949.x

[33] Oliveira, L.P.M., Jesus, R., Boulhosa, R.S., Mendes, C.M.C., Lyra, A.C. and Lyra, L.G.C. (2012) Metabolic Syndrome in Patients with Chronic Hepatitis C Virus Genotype 1 Infec- 
tion Who Do Not Have Obesity or Type 2 Diabetes. Clinics, 67, 219-223. http://dx.doi.org/10.6061/clinics/2012(03)03

[34] Mangia, A. and Ripoli, M. (2013) Insulin Resistance, Steatosis and Hepatitis C Virus. Hepatology International, 7, 782-789. http://dx.doi.org/10.1007/s12072-013-9460-1

[35] Bianchi, G., Marchesini, G., Zoli, M., Bugianesi, E., Fabbri, A. and Pisi, E. (1994) Prognostic Significance of Diabetes in Patients with Cirrhosis. Hepatology, 20, 119-125.

[36] Alberti, A., Vario, A., Ferrari, A. and Pistis, R. (2005) Chronic Hepatitis C-Natural History and Cofactors. Alimentary Pharmacology \& Therapeutics, 22, 74-78. http://dx.doi.org/10.1111/j.1365-2036.2005.02602.x

[37] Machado, M.V. and Cortez-Pinto, H. (2009) Insulin Resistance and Steatosis in Chronic Hepatitis C. Annals of Hepatology, 8, S67-S75.

[38] Patel, K., Thompson, A.J., Chuang, W.L., Lee, C.M., Peng, C.Y., Shanmuganathan, G., Thongsawat, S., Tanwandee, T., Mahachai, V. and Pramoolsinsap, C. (2011) Insulin Resistance Is Independently Associated with Significant Hepatic Fibrosis in Asian Chronic Hepatitis C Genotype 2 or 3 Patients. Journal of Gastroenterology and Hepatology, 26, 11821188. http://dx.doi.org/10.1111/j.1440-1746.2011.06722.x

[39] Hsu, C.S., Liu, C.H., Liu, C.J., Hsu, S.J., Chen, C.L., Hwang, J.J., Lai, M.Y., Chen, P.J., Chen, D.S. and Kao, J.H. (2010) Association of Metabolic Profiles with Hepatic Fibrosis in Chronic Hepatitis C Patients with Genotype 1 or 2 Infection. Journal of Gastroenterology and Hepatology, 25, 970-977. http://dx.doi.org/10.1111/j.1440-1746.2009.06186.x

[40] Yoneda, M., Saito, S., Ikeda, T., Fujita, K., Mawatari, H., Kirikoshi, H., Inamori, M., Nozaki, Y., Akiyama, T. and Takahashi, H. (2007) Hepatitis C Virus Directly Associates with Insulin Resistance Independent of the Visceral Fat Area in Nonobese and Nondiabetic Patients. Journal of Viral Hepatitis, 14, 600-607. http://dx.doi.org/10.1111/j.1365-2893.2006.00836.x

[41] Petta, S., Amato, M., Di Marco, V., Cammà, C., Pizzolanti, G., Barcellona, M.R., Cabibi, D., Galluzzo, A., Sinagra, D. and Giordano, C. (2012) Visceral Adiposity Index Is Associated with Significant Fibrosis in Patients with Non-Alcoholic Fatty Liver Disease. Alimentary Pharmacology \& Therapeutics, 35, 238-247. http://dx.doi.org/10.1111/j.1365-2036.2011.04929.x

[42] Ercin, C.N., Dogru, T., Genc, H., Celebi, G., Aslan, F., Gurel, H., Kara, M., Sertoglu, E., Tapan, S. and Bagci, S. (2015) Insulin Resistance but Not Visceral Adiposity Index Is Associated with Liver Fibrosis in Nondiabetic Subjects with Nonalcoholic Fatty Liver Disease. Metabolic Syndrome and Related Disorders, 13, 319-325.

http://dx.doi.org/10.1089/met.2015.0018 
Submit or recommend next manuscript to SCIRP and we will provide best service for you:

Accepting pre-submission inquiries through Email, Facebook, LinkedIn, Twitter, etc. A wide selection of journals (inclusive of 9 subjects, more than 200 journals)

Providing 24-hour high-quality service

User-friendly online submission system

Fair and swift peer-review system

Efficient typesetting and proofreading procedure

Display of the result of downloads and visits, as well as the number of cited articles

Maximum dissemination of your research work

Submit your manuscript at: http://papersubmission.scirp.org/

Or contact ojgas@scirp.org 